\title{
Beauty and the Welfare State
}

\author{
Periklis Polyzoidis \\ Associate Professor \\ Department of Social Administration and Political Science \\ Democritus University of Thrace \\ 1, PanagiTsaldari Street \\ Greece
}

\begin{abstract}
People spend billions of dollars on improving their image. Beautiful men and women are perceived as happier and more intelligent, trustworthy, successful and popular. There is plenty of scientific evidence that shows that physical appearance plays a significant role in political elections, education, the labor market, income and justice. All these findings lead to the plausible question of whether physical appearance has an impact on welfare provisions. The purpose of this paper is not to answer this question directly but to investigate whether it is worth exploring further. We discuss the possible impact of physical attractiveness on health and social security and attempt to discover its possible impact on social care through an empirical approach based on primary data collected by a survey targeting people who are active in social care organizations. The main conclusion is that physical attractiveness has an indirect impact on health services and social security and a marginal impact on social care provision.
\end{abstract}

Keywords: Physical attractiveness, beauty, welfare state, social care

\section{The power of beauty}

A survey of this kind can be easily criticized due to ignorance or prejudice and is controversial because some people may think that the impact of physical attractiveness on everyday life is so clear that it needs no further investigation, while others may think that correlating beauty with social welfare is blasphemy. In any case, the enormous sizes of the global beauty, fashion, and cosmetic surgery markets leave no doubt that people believe that physical appearance is important and that they actively try to look attractive.

The global fashion industry is divided into six main business segments: the luxury goods market, menswear industry, womenswear industry, bridal wear market, children's wear market, sports footwear market and some smaller segments (underwear, caps and shoes, accessories, etc.). Its estimated value is 3 trillion USD, or $2 \%$ of the world's GDP (Fashionunited, 2019). The global beauty market is divided into five main business segments, color (make-up), fragrances, haircare, skincare and toiletries (Barbalova, 2011). In 1997, global cosmetics and toiletries retail sales were 171.5 billion USD. At the end of the nineties, the global beauty marketwent through a slight slowdown, mostly due to a decline in sales in Asia-Pacific. Nevertheless, other regions, such as the US market (which grew 3\% to 5\%), reported further growth, primarily due to population growth and increasing demand for premium products (Bucalo, 1999). Fueled mostly by the emerging markets of Latin America and Asia, the global demand for cosmetics will continue to grow (Topaciuk and Toboda, 2013). The global market for cosmetic surgery segment involves reconstruction, restoration, and alteration of the human body and enhances the appearance of the body through both nonsurgical and elective surgical procedures. The market is expanding mainly due to social and cultural factors such as the influence of the film industry, media, and fashion, and it is estimated to reach a revenue of 21.97 billion USD by the end of 2023 (Market Research Future, 2019).

Thus, the question is to what extent is the enormous amount of money spent on beauty based on human vanity or a personal investment in a better life. The answer seems to be both. Spending on cosmetics and clothing has a positive impact on a woman's perceived beauty, as up to $10 \%$ of each unit of expenditure are repaid in the form of higher earnings (Hamermesh et al. 2002). Physiognomy (from the Greek word "physi" meaning "nature" and "gnomonas" meaning "guideline" or "set square") is the practice of assessing a person's personality and character from his/her outer appearance and especially the face and its expression. Physiognomy has a long history, as it is documented in both ancient Egypt and ancient Greece. 
Currently, nine out of ten people believe that physical features share information about an individual's behaviors (Zebrowitz, 1996). Moreover, psychologists record that physically attractive people are seen to possess a host of positive attributes, such as happiness, intelligence, trustworthiness, and success (Goldman and Lewis, 1977, Wilson and Eckel, 2006), a phenomenon that is commonly referred to as the physical attractiveness bias, or more simply,"what is beautiful is good" (Dion et al. 1972).

As we will see in more detail in the following sections, income and justice are two sectors for which there is plenty of scientific evidence that beauty is important. Nevertheless, these sectors are not the only ones. Scientific evidence shows that people prefer to interact with individuals who have attractive features. Physically beautiful people are consistently judged to be qualitatively superior and to have moral goodness, better interpersonal skills and enhanced mental acuity (Vashi, 2015). Those who are physically attractive reap many benefits, from higher average wages to a wider variety of mate choices (Oslen and Marshuetz, 2002). According to Kanazawa (2011), attractive children are more intelligent (by 12.4 IQ points in the United Kingdom and a somewhat smaller number of points in the United States). Physically attractive people are judged to be happier, more intelligent, more trustworthy and better adjusted than others (Dion et al. 1972, Goldman and Lewis 1977, Wilson and Eckel 2006). A person's physical appearance can have a substantial impact on popularity and treatment from others, in the sense that a more positive treatment of attractive women and men leads them to develop higher social skills and greater confidence, which can expand social networks, produce additional career opportunities, influence whom they choose as romantic partners and improve dating opportunities (Frederick et al., 2012). Facial characteristics influence impressions as they reveal psychological attributes whose detection is important for adaptive functioning. Adults with various childlike facial qualities are perceived to show more submission, honesty, warmth and naiveté and less physical strength than those with more mature faces (Berry and McArthur, 1986). Umberson and Hughes (1987) use status characteristics to explain the effects of attractiveness on well-being and achievement. They conclude that one's attractiveness does impinge on achievement and psychological well-being. Being very attractive reduces an individual's propensity for criminal activity and being unattractive increases it for a spectrum of crimes ranging from burglary to selling drugs. Unattractive females have lower labor force participation rates and have husbands who have a lower education (Hamermesh and Biddle 1994). The impact of physical appearance is also evident in the marriage market. Tall or obese women and short or unattractive men are less likely to be married (Harper, 2000).

Physical appearance plays a role in politics and education. Attractive children receive more attention in the classroom than do unattractive children. Moreover, teachers evaluate physically attractive students more favorably, and physically attractive students are perceived as belonging to a more socially desirable group (Clifford and Walster, 1973). A student's height, and even a student's name that sounds like it was given by uneducated parents, influence the student's human capital and skill formation during school. Names that signal lower socioeconomic status generate lower teacher expectations (Figlio, 2005). Height influences participation in club activities (Persico et al. 2004), enhancing the possibilityof a better social life. Physically attractive political candidates are seen as more trustworthy and are more likely to win elections than their less physically attractive competitors (Sigelman et al. 1987, Todorov et al. 2005). Physical attractiveness matters as a heuristic device for uninformed voters (but not for politically savvy voters). Stockemer and Praino (2015) asked students to rank the physical attractiveness of candidates to the U.S. House of Representatives, and then they asked one group to indicate their vote choice by merely looking at the picture of candidates, while another group hadthe pictures and detailed descriptions of the political and professional competencies of the contenders at their disposal. They found that those voters who are politically uninformed tend to cast their ballot for the better-looking candidate, whereas politically knowledgeable individuals choose the more competent candidate. Milazzo and Mattes (2016) explored the relationship between perceptions of candidate attractiveness and election outcomes in Britain using a computer-based survey to evaluate subjects' first impressions of real British candidates from the 2010 general election and found that candidates who were widely perceived to be more attractive had a higher vote share, even when the candidates' party, campaign spending, age, and incumbency were considered.

\section{The Sixth Day}

Although it is easy to observe the power and impact of beauty, it can be more informative to describe beauty itself. One problem is where to start: of course, we could measure and record the proportions of beautiful faces, but first, we need a set of proportions that define these faces as beautiful. As we will see, many scholars have tried over time to either define or measure beauty using a variety of different methods. A book written in 1753 describes six principles that independently affect beauty and grace: fitness (the impact of fitness on the total beauty of an object is only moderate, but it is a necessary cause), variety ("sameness", or a lack of variety, offends the senses), composed variety (only pleases us when it is suggestive of fitness), simplicity (enhances the pleasure of variety in that it pleases the eye), intricacy (beauty that is not obvious but needs to be discovered) and quantity (in a sense of greatness) (Hogarth, 1971). 
In everyday life, facial attractiveness is swiftly evaluated. Oslen and Marshuetz (2002) quickly showed pictures of faces to a group of people. These people were then asked to classify their feelings in words as either bad or good. Attractive faces resulted in speedy positive words and were found to be associated with eliciting positive emotions. Ambady and Rosenthal (1992) asked volunteers to rate teachers on traits including competence, confidence and honesty after watching 2-, 5- or 10-second silent clips of their performance. Two-second judgements were as accurate as those given more time, and the general scores successfully predicted the teachers' end of semester evaluations.

Studies have shown that faces high in symmetry are judged to be more attractive than faces low in symmetry (Hume and Montgomerie, 2001, Mealey et al. 1999). Symmetry is a major correlate of the physical attractiveness of men and women. When studies rely on an interview assessment rating of each candidate's beauty, interviewers may hold cultural and racial preferences that may insert bias into the studies (Zebrowitz and Montepare, 2008). To eliminate the impact of other features, Mealey et al. (1999) controlled for natural covariates of symmetry by comparing the symmetry and attractiveness differentials between monozygotic cotwins, who were genetically but not developmentally identical. They found that the more symmetric twin in each pair was consistently rated as more attractive and that the magnitude of the difference between the twins' perceived attractiveness was directly related to the magnitude of the difference in symmetry. Facial symmetry can be asserted with the use of a perceptual technique in which high symmetry is indicated by high ratings of the similarity between a left-left chimeric face and a right-right chimeric face ${ }^{1}$ (Mealey et al. 1999, Rhodes et al. 2001). In a simpler approach, research studies showed a number of photographs of men and women of all ages and races to two groups of people. The first group had to assess both the vertical and horizontal symmetry of these faces, and the second had to grade the same faces based on their own perception of beauty. People graded the faces that were previously rated as symmetrical more positively (Beck, 2010).

This link between symmetry and attractiveness comes from the idea that symmetrical faces are correlated with being healthy and more capable of reproducing (Hume and Montgomerie, 2001, Milne et al. 2003). Rhodes et al. (2001a) investigated whether averageness and symmetry signal health. They state that perceived health correlates negatively with distinctiveness and asymmetry. Facial distinctiveness ratings are associated with poor childhood health in males and poor current and adolescent health in females, while facial asymmetry is not associated with actual health. Fluctuating asymmetry (random deviations from perfect symmetry) is significantly associated with the number of medical conditions (asymmetric people more often report two or more medical conditions) (Milne et al. 2003). Symmetry has shaped the entire human civilization: almost everything created by humans is symmetric to a central vertical axis (cars, ships, glasses, tables, boxes, books, windows, paintings, doors, cables, beds, screws, bookmarks, bottles, mirrors, monitors, remote controllers, sponges, soaps, etc.), and we use other shapes only when there are limitations (rooms, buildings, complex machines). This is so obviously true that the average human brain needs some time to imagine that it could have been different.

Hume and Montgomerie (2001) explored the relationships between facial attractiveness and several variables thought to be related to genotypic and phenotypic quality in humans (fluctuating asymmetry, body mass index, health, age). They conclude that, although facial attractiveness is negatively related to developmental instability (as measured by asymmetry), attractiveness also signals different aspects of "quality" in both men and women. People with more symmetrical faces are associated with resisting disease, which signifies a healthy potential mate for passing along good genes. This preference for facial symmetry has become favored in evolution and is not just seen when choosing a mate but also in general judgements including an individual's "good" character. Rhodes et al. (2001a) examined whether facial averageness and symmetry are also attractive in non-Western cultures, manipulating the symmetry of Japanese and Chinese faces by blending each original face with its mirror image to create perfectly symmetric versions. They found that both Chinese and Japanese people preferred the perfectly symmetric versions to the original ones. On the other hand, Hatfield and Sprecher (1986) claimed that people in different cultures do not agree on which features are important, much less on what is good looking and what is not and suggest that, although there is considerable agreement about looks within a culture, there are no universal standards of beauty.

Another important component of beauty was accidentally discovered in a photographic experiment conducted for different reasons. Sir Francis Galton (knighted in 1909), an English scientist who was interested and active in almost all scientific fields of his time, created composite portraits in which he superimposed photographic exposures of faces registered on their eyes to create graphic representations of groups of faces such as criminals, meat eaters, vegetarians and tuberculosis patients using a technique called "composite portraiture".

\footnotetext{
${ }^{1}$ Chimeras are original full-face photographs split down a central vertical axis. Each individual side of the face is aligned with
} a mirror-reflected version of itself. 
He noticed that the composites were much better looking than their individual components because the special villainous irregularities had disappeared (Galton, 1878). It took a hundred years for the psychological scientific community to rediscover his initial observations and to pay attention to the beauty of these composed faces. Langlois and Roggman (1990) asked 300 people to rate the attractiveness of a series of 2-, 4-, 8-, 16-, and 32- computer processed composite photos of a large group of young male and female faces. They discovered that the larger the number of composite photos, the more attractive the outcome was, with the 32-composite faces being the most visually attractive of all other single or combined faces. These results led to the development of the concept of averageness, which describes the physical beauty that results from averaging the facial features of people of the same gender and age. It is clear that the average face is not a common face, as the term "average" strictly denotes the technical definition of the mathematical mean. In the following years, many studies using the same or different techniques, such as face profiles and line drawings, supported the original principle that average faces are consistently more attractive than the faces used to generate them.

On the Sixth Day of Creation, God said "Let Us make man in Our image..." (Genesis 1:27): The ideal standard mentioned above may represent something much more important than a simple rule of beauty.

\section{The seven rules of beauty}

Sitting comfortably on the shoulders of scientific giants and based upon their work, we suggest the following seven rules of beauty. We focus on the face, but there may be applications in other contexts as well.

1. Averageness. Thehuman brain has an enormous capacity to "read" faces. Its ability to automatically recognize familiar faces among billions of other faces is adequate proof. It seems that each brain constantly stores the faces it meets and creates composite images that represent the mean as an ideal standard. The fact that each person meets a very large number of faces during his or her lifetime results in almost (or perfect) identical ideal standards for all individuals. The closer a face is to this standard, the more it is perceived as beautiful. Averageness has two daughters: proportion and symmetry.

2. Proportion. The ideal standard reflects perfect proportions. Artists and scientists have tried to discover these proportions by measuring and comparing basic elements, such as distances from the eye pupil to the mouth edge, from hair to chin and from ear to ear, using two-dimensional models. The secrets of perfect beauty, though, are well hidden in the proportions between thousands of different elements, from head volume to the curve of the chin and from ear shape to eyelid length, three-dimensionally.

3. Symmetry. In beautiful faces, the left and right sides tend to be identical. Averageness ensures symmetry. In contrast to proportions, symmetry can be easily measured. Symmetry without averageness is not enough (i.e., a perfectly symmetrical face with two enormous ears).

4. Health. Absence of pimples, pustules, bruises, wounds, eye gums, blotches and any sign that disrupts the continuity of the skin or disfigures the shape of the face. Healthy hair and teeth.

5. Large eyes and a big mouth with full lips in relation to a small forehead, cheeks, nose, chin and ears. While the latter are static, eyes and mouth are the moving parts of the face and have the unique ability tobuild an expression. Dimples are welcome because they exaggerate the mouth and enhance the demonstration of emotions.

6. Rare color eyes such as blue (approximately $8 \%$ of the world population), hazel (5\%), amber (5\%), green (2\%) or gray (less than 1\%), and their shades (The world atlas, 2019). Rare colors will vanish in the future. Both parents must contribute a rare color eye gene to obtain a rare color eyed baby. If both parents have one copy of the rare gene and one copy of the dominant brown-eyed gene, then there is only a $25 \%$ possibility that the rare colorwill emerge.

7. Childbearing age (neither too old nor too young), attractive voice and smell (both difficult for a non-poet to describe).

Plastic surgeons and experienced beauticians apply their techniques to improve proportions, restore symmetry, hide unhealthy signs, and remove or restrict nonmoving parts, while highlighting the eyes and the mouth, highlighting (or creating the illusion of) rare color eyes and repairing the signs of aging. Although there is no universal prototype, the seven rules are valid across cultures and centuries: the standard is changing because people are changing.

\section{Effects of beauty on income and justice}

\section{1. "Show me your picture, and I'll tell you your income"}

More attractive people are more likely to be employed and earn higher wages. Attractive employed people, especially men, older employed people, and those engaged in occupations primarily filled by men earn higher annual salaries than less attractive respondents. Younger and female people and those working in jobs largely performed by women, however, tend not to gain any significant economic returns from greater physical attractiveness (Roszell et al. 1989). 
More attractive men have higher starting salaries and continue to earn more over time, while for women, there is no effect of attractiveness on starting salaries, but more attractive women earn more later on in their jobs (Hanson Frieze et al. 1991). The wage effects of attractiveness are positive across the entire wage distribution and are nonlinear for men (meaning that the wage premium for attractiveness is smaller than the wage punishment for unattractiveness) and linear for women (Pfeifer, 2012).

Hamermesh and Biddle (1998) propose models with an ascriptive characteristic generating earnings differentials and causing sectoral sorting, which allow us to distinguish among sources producing such differentials. Beautiful people are seen to be more competent, are perceived more favorably by potential employers, are more likely to be hired and are more likely to receive higher wages and promotions (Bóo et al. 2013, Hamermesh and Biddle 1993, Harper 2000). Physical appearance has a substantial effect on employment patterns and earnings. Men and women assessed as unattractive or short experience a significant earnings penalty. Tall men receive a pay premium, while obese women experience a pay penalty (Harper, 2000). There is evidence of labor market discrimination against obese women. While the results for men are weaker and mixed, obese women have lower family incomes than women whose weight-forheight is in the 'recommended' range (Averett and Korenman, 1993). At a higher level, companies with physically attractive CEOs earned significantly higher stock returns than those with comparably less attractive CEOs (Rule and Ambady, 2008).

\subsection{Angels and demons in front of the jury}

There is plenty of evidence that the criminal justice system does privilege physically attractive defendants and can be divided into four major categories: studies that show that attractiveness influences juridical decisions in general, studies that show that there is influence only on less severe offenses, and studies that show that attractiveness does not influence the judgment itself but does influence the length of the sentence. Another group of scholars refers to a reverse effect, whereby the beauty of the defendant can result in a more severe punishment.

Juries in both mock and real trials tend to be more lenient toward more attractive defendants than toward their less attractive counterparts (Buck and Tiene, 1989, Darby and Jeffers 1988, Leventhal and Krate 1977). Attractiveness of the offender could have very well acted as an extralegal factor in trialsin which attractiveness was rewarded with a more lenient sentence (Sporer and Goodman-Dclahunly, 2009). Mocan and Tekin (2006) have suggested that unattractive individuals face a handicap. The level of beauty in adolescence has an effect on criminal propensity some years later, probably due to the impact of the level of beauty on human capital formation. The derived labor market penalty provides a direct incentive for unattractive individuals to engage in criminal activity. Stewart (1980) conducted a study using the attractiveness ratings of defendants and reported that in $90 \%$ of the cases, the more attractive the defendant, the more lenient was the sentence. Criminals who have had plastic surgery to enhance their features have a greater change of not returning to prison (Lewison, 1974).

Hamermesh and Biddle (1994) investigated the relationship between attractiveness (ratings assigned by interviewers on a scale from 1 to 5) and the criminal activity of young adults aged 18 to 26 . Although they detected no unfavorable treatment of unattractive individuals or males, they noticed that very attractive females receive favorable treatment from the criminal justice system, as they were less likely to be detained. A study that examined the effect of gender and facial characteristics of criminal offenders on attributions of crime-relevant traits showed slight tendencies toward more lenient appraisals of the more attractive women (Ahola et al. 2009).

Some studies find that physically attractive defendants are less likely to be found guilty, and even those who are convictedreceive shorter sentences (Efran 1974, Leventhal and Krate 1977, Darby and Jeffers 1988, Desantis and Kayson 1997). In severe cases, physical attractiveness did not influence whether the defendant was acquitted or convicted, but it did influence sentence length (Stewart, 1980, 1985). In negligent homicide cases, both physically attractive and unattractive defendants were declared guilty at equal rates; however, when they were sentenced, physically attractive defendants were sentenced more leniently than unattractive defendants (Landy and Aronson, 1969).

Other scholars have suggested that observations of the attraction-leniency effect are limited to less severe and victimless offenses (Downs and Lyons 1991, Mazzella and Feingold 1994, Beckham et al. 2007).

After applying more realistic jury simulations or controlling for seriousness of crime and race, the effects of physical attractiveness on legal leniency disappear altogether (Weiten 1994, Kutys 2013). A study thatanalyzed data on male property, drug, and violent offenders to examine the relationship between sentencing outcomes and physical attractiveness showed that although physical attractiveness is not related to sentencing outcomes among drug offenders and those without a prior criminal record, physically attractive criminal defendants are less likely to be sentenced to 
prison than their less physically attractive counterparts (Fraga,2015). Sigall and Ostrove (1975) combined the physical attractiveness of a criminal defendant and the nature of the crime (attractiveness-unrelated or attractiveness-related) in a factorial experiment, asking a large number of students to sentence the defendant to a term of imprisonment, and found out that when the offense was attractiveness-related, the attractive defendant would receive harsher treatment, but when a crime was unrelated to attractiveness (burglary) the students would assign more lenient sentences to the attractive defendant than to the unattractive defendant. Based on an assessment of the physical attractiveness of over 2,000 female and male defendants by police officers, Downs and Lyons (1991) conclude that the physical attractiveness of defendants is a significant predictor of fines and bail amounts for misdemeanor charges but not for more serious felony charges.

Finally, some researchers even find a reverse effect, in which physically attractive defendants receive harsher punishment than less attractive ones (Escott 2005, Patry, 2008). In some instances, there seems to be a penalty for beauty. In these cases, the more attractive criminals receive a harsher sentence, and it seems that a pity factor develops and the tattooed, overweight, obese, scarred, and unattractive criminals receive the more lenient sentence (Beck, 2010). Mazzella and Feingold (1994) asked people to rate whether defendants appeared attractive, confident, dirty, educated, good, of good posture, rich, sloppy and well-dressed and found that a harsh sentence was given to the more attractive defendant in cases of negligent homicide while an attractive person who committed theft or rape received a less harsh sentence.

\section{The (in)visible factor: physical appearance in health services and social security}

Social protection, the outcome of the welfare state (or welfare regime, which besides the state also includes the market and the nonprofit sector), is divided into three pillars: health, social security and social care. With regard to health, social protection includes everything that is related to prevention, cure and rehabilitation but is not the direct subject of medicine. It includes the design and management of health services. From this point of view, external appearance has no direct impact on social protection because it is clear that health planning is uniform for all people, regardless of physical appearance.

However, considering the extensive literature that suggests that rich people have access to better health services (the Black report, Gray, 1982) on the one hand and the fact that, as mentioned above, beautiful people achieve better salaries on the other hand, we can theoretically conclude that beauty does indirectly affect the equal distribution of health services. Similar remarks can be made regarding the social security pillar. In contrast to social care, which includes personal (nonmonetary) services, social security includes social transfers (in cash or in kind) such as old-age and survivors' pensions, and unemployment, family-related, sickness, disability and other benefits. These benefits may be either contributory (such as an unemployment allowance, where the entitlement depends on previous payments) or noncontributory, where the allowance depends on conditions independent of previous payments (such as benefits for natural disaster victims). Neither access to the latter nor their amount can be affected by beauty. Regarding contributory benefits, however, things are different. The largest proportion of contributory benefits are pensions that compensate for a percentage of the salary earned by the pensioner during his or her career. Since, as mentioned earlier, the amount of this salary depends on appearance, we can theoretically and inductively assume that beauty affects not only health services but also some aspects of social security.

\section{The effect of social care service users' appearance on social care providers: an empirical approach}

The evident effects of physical appearance on various sectors of social interaction described above lead to the plausible question of whether appearance also has an impact on the fair contribution of health and social benefits and services. Our ambition is not to directly answer this question that challenges the holy cow of the welfare state andthe very core of its principles but only to investigate whether there is some impact worthy of further research. The subject is innovative and so there is no standard methodology, nor is it possible to take advantage of methods used in other sectors (such as education, the legal system or the labor market) as described above. The only way to gain knowledge is to directly ask the opinion of executives and experts active in welfare state organizations.For these reasons, we chose a sample of 1000 employed and volunteer social workers, psychologists, nurses, and administration and auxiliary staff active in public, private and nonprofit organizations who provide social care services for homeless people, people with disabilities, prisoners and ex-prisoners, elderly people, victims of domestic violence, drug and alcohol addicts, refugees, migrants, Roma people, poor, ethnic and religious minority groups, members of the LGBT community, people in need of blood, and the mentally or physically ill, and sent them a brief questionnaire consisting of 14 questions asking them not for their personal opinion but about what they witness in the field in which they are active. There were two sets of positive and negative questions. The first set consisted of 7 questions asking whether some positive characteristics of the recipients of social services motivate the staff to provide better services, while the second set consisted of 7 questions asking whether the following negative characteristics of the recipients of social services 
motivate the staff to provide worse services (table 1). This approach is far from perfect because it does not cover opposite reactions, i.e., negative characteristics that motivate better services because they cause feelings of pity or positive characteristics that motivate worse services because they cause feelings of jealousy, but as stated earlier, our humble aim was to simply investigate whether there is some impact and not to entirely analyze this impact.

\begin{tabular}{|l|l|}
\hline \multicolumn{2}{|c|}{ Table 1. Positive and negative attributes } \\
\hline positive attributes & negative attributes \\
\hline clean face and body & dirty face and body \\
\hline neat clothing and shoes & dirty and neglected clothing and shoes \\
\hline tall and straight figure & short and hunched figure \\
\hline normal body weight & obesity \\
\hline beautiful hair & dirty and neglected hair \\
\hline beautiful face & ugly face \\
\hline healthy teeth & rotten teeth \\
\hline
\end{tabular}

A 5-point Likert scale was chosen (Strongly Disagree, Disagree, Neither Disagree nor Agree, Agree, and Strongly Agree) afterthorough research because it combines adequacy with simplicity and provides an option for a neutral choice. The small rate of return (149 responders, 14.9\%) probably signifies a limited concern of the responders about the issue: in a very similar sample of research regarding job satisfaction, the rate of return was more than double (32.6\%). There were 345 total visits, 192 unique visitors and a $77.6 \%$ completion rate. Respondents were $23 \%$ male and $77 \%$ female. Of these, $62 \%$ were active in the public sector, $15 \%$ in the private sector and $32 \%$ in the nonprofit sector. Seven respondents were volunteers. Tables 2 and 3 summarize the results. As we can see, the respondents were decisive. There is no question where the majority chose the "neither/nor" option.

\begin{tabular}{|l|l|l|l|}
\hline \multicolumn{5}{|c|}{ Table 2. Percentage of agreement/disagreement that positive attributes motivatebetter services (higher values } \\
in bold) \\
\hline Attribute motivates better services & $\begin{array}{l}\text { Disagree and } \\
\text { Strongly Disagree }\end{array}$ & Neither Disagree nor Agree & $\begin{array}{l}\text { Agree and Strongly } \\
\text { Agree }\end{array}$ \\
\hline clean face and body & 10.2 & 18.4 & $\mathbf{7 1 . 5}$ \\
\hline neatclothing and shoes & 18.5 & 22.6 & $\mathbf{5 8 . 9}$ \\
\hline tall straight figure & $\mathbf{3 7 , 4}$ & 26,5 & 36 \\
\hline normal body weight & $\mathbf{4 3 , 5}$ & 27,9 & 28,6 \\
\hline beautiful hair & $\mathbf{4 4 , 9}$ & 24,5 & 30,6 \\
\hline beautiful face & 30,6 & 17,7 & $\mathbf{5 1 , 7}$ \\
\hline healthy teeth & 36,7 & 31 & $\mathbf{4 2 , 2}$ \\
\hline AVERAGE & 31,68 & 24,08 & $\mathbf{4 5 , 6 4}$ \\
\hline
\end{tabular}

Regarding positive attributes, we see that in four out of seven cases, the majority agree or strongly agree that the respected attributes do motivate better services, while in the other three cases, the majority disagree or strongly disagree. The average is 45,64\% agree/strongly agree, 31,68 disagree/strongly disagree and 24,8 neither agree nor disagree.

\begin{tabular}{|l|l|l|}
\hline \multicolumn{5}{|l|}{ Table 3. Percentage of agreement/disagreement that negative attributes motivate worse services (higher values } \\
in bold)
\end{tabular}


The results are different with regard to negative attributes, where for only two out of the seven attributes (dirty face and body, dirty and neglected clothing and shoes), the majority agree or strongly agree that there is motivation for worse services. In all other cases (five out of ten), the majority disagree or strongly disagree, with an average of 32,32\% agree/strongly agree, 22,4 disagree/strongly disagree and 45,21 neither agree nor disagree. The total average (both positive and negative attributes) is 38,445\% disagree/strongly disagree, $23,4 \%$ neither disagree nor agree and 38,98\% agree/strongly agree. Regarding positive attributes, the majority of men agree that there is motivation in all 7 cases, while the majority of women agree that there is motivation in 5 cases and disagree in 2 cases (body weight, hair). Regarding negative attributes, the majority of men agree that there is motivation in 2 cases and disagree in 5 cases, while the majority of women disagree that there is motivation in all 7 cases, with a percentage tending toward $100 \%$. In general, men report that there is an impact (agree/strongly agree) more often than women ( 9 versus 5 cases in total).

\section{Conclusion}

We split the entire spectrum of social protection into three pillars: health service, social security (social benefits) and social care (personal social service). Considering the first one, if we take into account that it is easier for physically attractive people to find a job, to be promoted and to win more money, then it is clear that they can also claim better health services, especially in the Greek health system where high out-of-pocket health payments are the rule. Regarding the second pillar, social security, if we consider that pensions comprise the lion share of social security benefits (in all South European countries and especially in Greece) and that pensions are related to previous wages, it is more possible for physically attractive men and women to achieve higher pensions. The conclusions of our empirical approach regarding the third pillar, social care, are not clear. The majority of respondents agreed that physical appearance has a (positive or negative) effect on the level of service, but the difference from the opposite opinion is extremely marginal (only $0.535 \%$ ), which means that different sets of attributes could easily lead to different conclusions. Nonetheless, it is worth mentioning that although most respondents agree/strongly agree that positive attributes do motivate better services ( 4 out of 7 cases, $45 \%$ on average), the majority disagree/strongly disagree that negative attributes motivate worse services (5 out of 7 cases, 45,21\% on average). Our research does not go deep enough to explain the reasons for that. One explanation could be that social care providers are used to interacting with people who bear negative attributes, so they do not pay attention to these, but they are not used treating people who bear positive attributes, so they pay more attention and help slightly more when such (rare) cases occur. A number of appropriate in-depth interviews could shed some light on these phenomena.

\section{Refereance}

Ahola A. S. , Christianson Sven, A. \&Hellström, А. (2009). Justice needs a blindfold: Effects of gender and attractiveness on prison sentences and attributions of personal characteristics in a judicial process. Journal of Psychiatry, Psychology and Law, (16)1, 90-100.

Ambady, N. ,\& Rosenthal, R. T. (1992). Slices of expressive behaviour as predictors of interpersonal consequences: A meta-analysis. Psychological Bulletin, 111(2), 256-274.

Averett, S. ,\&Korenman, S. (1993). The economic reality of the beauty myth. NBER Working Paper No. 4521.

Barbalova, I. (2011). Global beauty and personal care: the year in review and winning strategies for the future. Incosmetics. Euromonitor, International Global Beauty and Personal Care.

Beck, K. (2010). Do ugly criminals receive harsher sentences? An analysis of lookism in the criminal justice system. Business and Economics Honors Papers. Ursinus College.

Beckham, C. M. , Spray, B. J. \&Pietz, C. A. (2007). Jurors' locus of control and defendants' attractiveness in death penalty sentencing. The Journal of Social Psychology, 147(3), 285-298.

Berry, D. S. \& McArthur, L. Z. (1986). Perceiving character in faces: The impact of age-related craniofacial changes on social perception. Psychological Bulletin, 100(1), 3-18.

Bóo, F. L. ,Martín, R. A. \& Sergio, S. U. (2013). The labour market return to an attractive face: Evidence from a field experiment. Economic Letters, 118(1), 170-172.

Bucalo, A. (1999). State of the industry. The emerging markets march forward. Global Cosmetics Industry.

Buck, S. \& Tiene, D. (1989). The impact of physical attractiveness gender and teaching philosophy on teachers' evaluations. Journal of educational Research, 82(3), 172-177.

Clifford, M. \&Walster, E. (1973). The effect of physical attractiveness on teacher expectations. Sociology of Education, 46, 248-258.

Darby, B. W. \& Devon, J. (1988). The effects of defendant and juror attractiveness on simulated courtroom trial decisions. Social Behaviour and Personality, 16(1), 39-50. 
Desantis, A. \& Kayson, W. A. (1997). Defendants' characteristics of attractiveness, race, sex and sentencing decisions. Psychological Reports, 81(2), 679-683.

Dion, K. ,Berscheid, E. \&Walster, E. (1972). What is beautiful is good. Journal of Personality and Social Psychology, 24(3), 285-290.

Downs, A. C. \& Lyons, P. M. (1991). Natural observations of the links between attractiveness and initial legal judgments. Personality and Social Psychology Bulletin, 17(5), 541-547.

Efran, M. G. (1974). The effect of physical appearance on the judgment of guilt, interpersonal attraction, and severity of recommended punishment in a simulated jury task. Journal of Research in Personality, 8(1), 45-54.

Escott, E. J. (2005). The attraction-leniency effect: Ambiguity, attractiveness type, and a reverse attraction-leniency bias. $\mathrm{PhD}$ dissertation.

Fashionunited (2019). Global fashion industry statistics - International apparel [online] Available: https://fashionunited.com/global-fashion-industry-statistics/ (June 1, 2019).

Figlio, D. N. (2005). Names, expectations and the black-white test score gap. NBER Children, Economics of Education Working Paper, No. 11195.

Fraga, A. (2015). Pretty probationers: The relationship between physical attractiveness and sentencing outcomes. Ohio State University.

Frederick, D. A. , Reynolds, T. A. , Fales, M. R. , \& Garcia, J. R. (2012). Physical attractiveness: Dating, mating, and social interaction. Encyclopedia of Body Image and Human Appearance 2, 629-635.

Galton, F. (1883). Composite portraits. Journal of the Anthropological Institute of Great Britain and Ireland, 8, 132142.

Goldman, W. \& Lewis, P. (1977). Beautiful is good: Evidence that the physically attractive are more socially skilful. Journal of Experimental Social Psychology, 13(2), 125-141.

Gray, A. M. (1982). Inequalities in health. The Black Report: a summary and comment. International Journal of Health Service, 12(3), 349-380.

Hamermesh, D. S. \& Biddle, J. E. (1993). Beauty and the labour market. Working paper no. w4518, National Bureau of Economic Research.

Hamermesh, D. S. \& Biddle, J. E. (1998). Beauty, productivity, and discrimination: Lawyers' looks and lucre. Journal of Labor Economics,16(1), 172-201.

Hamermesh, D. S., Meng, X.\& Zhang, J. (2002). Dress for success - does primping pay? Working Paper 7167, National Bureau of economic research,Labour Economics.

Hanson, I. , Olson, F. \& Russell, J. E. (1991). Attractiveness and income for men and women in management. Journal of Applied Social Psychology, 21(13),1039-1057.

Harper, B. (2000). Beauty, stature and the labour market: a British Cohort Study. Oxford Bulletin of Economics and Statistics, 62(1), 771-800.

Hatfield, E. \&Sprecher, S. (1986). Mirror, mirror: The importance of looks in everyday life. Albany: State University of New York Press.

Hogarth, W. (1971). The analysis of beauty (1753). New Haven and London: Yale University Press.

Hume, D. K. \& Montgomerie, R. (2001). Facial attractiveness signals different aspects of "quality" in women and men. Evolution and Human Behaviour, 22, 93-112.

Kanazawa, S. (2011). Intelligence and physical attractiveness Intelligence, 39(1), 7-14.

Kutys, J. M. (2013). Juror Decision Making: The impact of attractiveness and socioeconomic status on criminal sentencing and an examination of motivated reasoning in mock jurors. PhD Dissertation, Wright State University.

Landy, D. \& Aronson, E. (1969). The influence of the character of the criminal and his victim on the decisions of simulated jurors. Journal of Experimental Social Psychology, 5(2), 141-152.

Langlois, J. H. \&Roggman, L. A. (1990) Attractive faces are only average. Psychological Science, 1(2), 115-121.

Leventhal, G. \&Krate, R. (1977). Physical attractiveness and severity of sentencing. Psychological Reports, 40(1), 315318.

Lewison, E. (1974). Twenty years of prison surgery: an evaluation. Canadian Journal of Otolaryngology, 3, 42-50.

Market Research Future (2019). Cosmetic surgery market: Trends and analysis: Growth revenue and cost analysis with key company's profiles, forecast to 2023. https://www.marketresearchfuture.com

Mazzella, R. \& Feingold, A. (1994). The effects of physical attractiveness, race, socioeconomic status, and gender of defendants and victims on judgments of mock jurors: A meta-analysis. Journal of Applied Social Psychology, 24(15), 1315- 1133. 
Mealey, L. ,Bridgstock, R. \& Townsend, G. C. (1999). Symmetry and perceived facial attractiveness: A monozygotic co-twin comparison. Journal of Personality and Social Psychology, 76(1), 151-158.

Milazzo, C. \& Mattes, K. (2016). Looking good for election day: Does attractiveness predict electoral success in Britain? The British Journal of Politics and International Relations, 18(1), 161-178.

Milnea, B. J., Belskyb, J., Poultona, R., Thomsonc, W. M. ,Caspid, A. \&Kieserc, J. (2003). Fluctuating asymmetry and physical health among young adults. Evolution \& Human Behavior 24, 53-63.

Mocan, N. \&Tekin, E. (2006). Ugly criminals. Cambridge: National Bureau of Economic Research, 200b. NBER Working Paper Series.

Olson, I. R. \&Marshuetz, C. (2005). Facial attractiveness is appraised in a glance. Emotion, 5, 498-502.

Patry, M. (2008). Attractive but guilty: Deliberation and the physical attractiveness bias. Psychological Reports, 102(3), 727-733.

Persico, N. ,Postlewaite, A. \& Silverman, D. (2004). The effect of adolescent experience on labor market outcomes: the case of height. Journal of Political Economy, 116 (3), 1019-1053.

Pfeifer, C. (2011). Physical attractiveness, employment and earnings. Applied Economics Letters, 19(6), 505-510.

Rhodes, G. , Yoshikawa, S., Clarkô, A. , Leeô, K. , McKayô, R., Akamatsu, S. (2001b).Attractiveness of facial averageness and symmetry in non-Western cultures: In search of biologically based standards of beauty. Perception, 30, 611- 625.

Rhodes, G. ,Zebrowitzb, L. A. , Clarka, A., Kalickc, M. S., Hightowera, A. \&McKaya, R. (2001a). Do facial averageness and symmetry signal health? Evolution and Human Behavior, 22, 31-46.

Roszell, P. , Kennedy, D. \&Grabb, E. (1989). Physical attractiveness and income attainment among Canadians. The Journal of Psychology, 123(6), 547-559.

Rule, N. O. \& Nalini, A. (2008). The face of success inferences from chief executive officers' appearance predict company profits. Psychological Science 19(2), 109-111.

Sigall, H. \&Ostrove, N. (1975). Beautiful but dangerous: Effects of offender attractiveness and nature of the crime on juridical judgment. Journal of Personality and Social Psychology, 31(3), 410-414.

Sigelman, L. ,Sigelman, C. K. \& Fowler, C. (1987). A bird of a different feather? An experimental investigation of physical attractiveness and the electability of female candidates. Social Psychology Quarterly, 50(1), 32-43.

Sporer, S. L. \& Goodman-Delahunty, J. (2009). Disparities in sentencing decisions. In M. E. Oswald, S. Bieneck\& J. Hupfeld-Heinemann (Eds.), Social Psychology of Punishment and Crime, (pp. 379-401).New York: John Wiley \& Sons.

Stewart, J. (1985). Appearance and punishment: The attraction-leniency effect in the courtroom. The Journal of Social Psychology 125(3), 373-378.

Stewart, J. E. (1980). Defendant's attractiveness as a factor in the outcome of criminal trials: An observational study. Journal of Applied Social Psychology, 10, 348-361.

Stockemer, D. ,\&Praino, R. (2015). Blinded by beauty? Physical attractiveness and candidate selection in the U.S. House of Representatives. Social Science Quarterly 96(2), 215-232.

The word atlas. The World's Population by eye colour percentages [online] Available: https://www.worldatlas.com/articles/which-eye-color-is-the-most-common-in-the-world.html (1 June 2019).

Todorov, A. Anesu, N. , Goren, M. A. \& Hall, C. C. (2005). Inferences of competence from faces predict election outcomes. Science, 308(5728), 1623-1626.

Topaciuk, A., \& Łoboda, M. (2013). Global beauty industry trends in the 21 st century. Active citizenship by knowledge management an innovation. Managment, Knowledge and learning, 19-2. Zadar.

Umberson, D. \& Hughes, M. (1987). The impact of physical attractiveness on achievement and psychological wellbeing. Social Psychology Quarterly, 50(3), 227-236.

Vashi, N. (2015). Historical importance of beauty. In: N. Vashi (Ed.), Beauty and body dysmorphic disorder. (pp 1-16). Cham: Springer.

Weiten, W. (1980). The attraction-leniency effect in jury research: An examination of external validity. Journal of Applied Social Psychology, 10(4), 340-347.

Wilson, R. K., \& Eckel, C. C. (2006). Judging a book by its cover: Beauty and expectations in the trust game. Political Research Quarterly, 59(2), 189-202.

Zebrowitz, L. A. (1996). Physical appearance as a basis of stereotyping. In C. Neil Macrae, C. Stangor\& M. Hewstone (Eds.), Stereotypes and stereotyping (pp. 79-120). New York: Guilford Press.

Zebrowitz, L. A. \& Montepare, J. M. (2008). Social psychological face perception: Why appearance matters. Social and Personality Psychology Compass 2(3), 1497-1517. 